\title{
Preparation and Characterization of High Methanol Resistance Sulfonated Poly(ether ether ketone) Membrane for DMFC Application
}

\author{
J. Jaafar ${ }^{1} \&$ A. F. Ismail $2^{*}$ \\ ${ }^{1 \& 2}$ Faculty of Chemical and Natural Resources Engineering, Universiti Teknologi Malaysia, 81310, UTM Skudai, \\ Malaysia
}

\begin{abstract}
High methanol resistance sulfonated poly(ether ether ketone) (SPEEK) membranes have been prepared and characterized as a potential proton exchange membrane for direct methanol fuel cell. The sulfonation process was conducted at room temperature to produce SPEEK with $60 \%$ degree of sulfonation (DS). The produced membranes were then characterized by evaluating the swelling behavior in terms of water uptake, swelling ratios and methanol sorption as a function of temperature and reaction time. Interestingly, it was observed that the methanol uptake value of SPEEK membrane was lower as compared to the water uptake value as much as $80 \%$. This characteristic showed that SPEEK membrane possesses good resistance towards methanol which is a crucial property requires for direct methanol fuel cell (DMFC) application.
\end{abstract}

Keywords: SPEEK, swelling behavior, methanol uptake, DMFC

\subsection{INTRODUCTION}

The employment of liquid methanol in direct methanol fuel cell (DMFC) instead of hydrogen fuel offers several advantages, including easier storage and more straightforward implementation because humidification and thermal management, fuel vaporizer or reformer are no longer needed. However, the DMFC has the disadvantages of the methanol crossover through the commercially used perfluorosulfonic acid membranes such as Nafion (DuPont), Dow (Dow Chemicals) and Flemion (Asahi Glass) [1].

It is accepted that Nafion particularly has a dual structure with a hydrophobic region interspersed with ion-rich hydrophilic domains. The pore sizes of the latter domain are inaccessible by decane (and octane) molecules but accessible by water molecules. It is known that methanol

* Correspondence to: A. F. Fauzi (email: afauzi@utm.my) diffuses primarily through the water-rich domains. Thus, the pronounced water-rich domains in Nafion membranes must affect the rate of methanol cross-over which is unessential in DMFC applications [2].

In fact, membranes with high performance, which is described in terms of high proton conductivity and low methanol permeability, are highly crucial as separators and electrolytes in DMFC. DMFC also demands on the material and production costs of proton exchange membranes (PEMs) manufacturing. These circumstances stimulate a research into alternative PEM materials, which can overcome the aforementioned problems that can be produced economically.

Attempts to produce alternative PEM to fulfill DMFC requirements have been carried out on aromatic polymers such as polyethersulfone (PES), poly(ether ether ketone), polyphenylquinoxaline (PPQ) and polybenzimidazole (PBI). Among the aforementioned polymers, PEEK is considered to be the most promising polymer 
owing to good thermal, chemical and mechanical stability, commercially available and very low cost.

In order to reduce the difficulty in processing the aromatic PEEK polymers, more flexible linking groups are often attach between the aromatic rings. Linking groups that impart good flexibility while still maintaining good thermal properties include ketones, sulfones, sulfides, oxides and perfluoroakyl groups [3]. In particular, PEEK doped with strong acid exhibits stable proton conductivity at temperature higher than $100^{\circ} \mathrm{C}$. Therefore, sulfonic acid group is the most promising candidate to be linked into the polymer structure via sulfonation process. It is a simple process reaction and required shorter overall reaction time as compared to other processes, hence reduced the membrane production cost [4].

Sulfonating agent is one of the important factors in order to enhance the reactivity of sulfonation process. The sulfonating agents such as concentrated sulfuric acid, chlorosulfonic acid, pure or complex sulfur trioxide, and acetyl sulfide are among those that have been used in sulfonation process. Frequently, researchers employed concentrated sulfuric acid as the sulfonating agent for sulfonated of PEEK [5-8]. This is because sulfuric acid can prevent crosslinking reaction and polymer degradation effect during the sulfonation process with $100 \%$ sulfuric acid or chlorosulfonic acid as sulfonating agents. However, the degree of sulfonation (DS) can be controlled by changing reaction time, temperature and acid concentration by diluting strong acid such as fuming sulfuric acid with concentrated sulfuric acid $[9,10]$. Occasionally, fuming acid or diluted fuming acid with concentrated sulfuric acid were utilized for sulfonated PEEK [11-13]

In order to further develop an understanding on the sulfonated PEEK, therefore the SPEEK membranes have been prepared using a proprietary mixture of fuming sulfuric acid and sulfuric acid as the sulfonating agent. Optimiztion of the surfroting agent mixtures represents the most inventice step in devloping this SPEEK PEM for DMFC. This step leads to both high ion exchange capacity (IEC) and DS of the membran within 2 to 3 hours compared 120 hours usin conventional methods reported by Zaidi et al. [9]
The SPEEK membranes developed were then characterized in terms swelling behaviors by evaluating the water uptake, swelling effect and methanol uptake as a function of temperature and reaction time.

\subsection{METHODS/THEORY}

\subsection{Materials}

PEEK polymer was obtained from Victrex US Inc. Ltd. in powder form. Concentrated sulfuric acid (95-98\%) and fuming sulfuric acid (15-30\%) were provided by Fisher Scientific. Aldrich Chemical Co. Inc. provides the $\mathrm{N}$-methyl pyrrolidone (NMP) as solvent for SPEEK membrane preparation. Nafion 115 (DuPont) was used as a reference material

\subsection{Sulfonation Process}

Sulfonation reactions were conducted at room emperature using mixtures of $15-30 \%$ fuming sulfuric acid and $95-98 \%$ of concentrated sulfuric acid as the sulfonating agent for poly(ether ether ketone) (PEEK). 25 g PEEK and $400 \mathrm{~mL}$ (total acid used) of sulfonating agent used was magnetically stirred at room temperature and under itrogen atmosphere for 6 hour to obtain sulfonated PEEK with $60 \%$ DS. The produced sulfonated PEEK polymer was recovered by precipitating the acid polymer solution into a arge excess of ice cubes. The resulted sulfonated EEK polymer was wash distilled water until the $\mathrm{pH} \sim 6$ to 7 . SPEEK pory $80-100^{\circ} \mathrm{Co}$. 24 was dried in the drying oven at

\subsection{Membrane Preparation}

20 wt.\% of SPEEK solution was prepared by dissolving SPEEK polymer in N-Methyl pyrrolidone (NMP) under continuous stirring at room temperature for several hours until the sulfonated PEEK polymer dis hours until the sulfonated SPEEK solution obtained was then degassed in an ultrasonic bath at room temperature in order to eliminate air bubbles. The menbranes were cast onto a glass plate with a thickness in the range of $50 \mu \mathrm{m}$ to $150 \mu \mathrm{m}$. Then, the cast membranes were dried at $60^{\circ} \mathrm{C}$ for $6 \mathrm{~h}$ followed by drying at $100^{\circ} \mathrm{C}$ for $4 \mathrm{~h}$. After cooling to room drying ature the resultant membranes were peeled from the glass in water and then residual solvent was removed by drying for 3 days in a vacuum oven kept at $120^{\circ} \mathrm{C}$. Finally, the membranes were treated with $1 \mathrm{M}$ sulfuric acid solutions for 1 day at room temperature and subsequently rinsed with water several times.

\subsection{FTIR}

FTIR spectra for SPEEK samples were recorded using Nicolet-Magna 560 IR Spectrometer with powder samples inside a diamond cell and operated at room temperature in the range of 600 to $1800 \mathrm{~cm}^{-1}$ wave length.

\subsection{Swelling Behavior}

The swelling behaviors of the resulting membranes were studied as a function of water and methanol uptakes, respectively. The sulfonated membranes were dried in an oven at $60^{\circ} \mathrm{C}$ for $48 \mathrm{~h}$, weighed films with diameter $\sim 5.0 \mathrm{~cm}$ then soaked in water and methanol overnight at room temperature, blotted dry with absorbent paper to remove any surface moisture, and reweighed. The water uptake experiment was repeated by soaking membranes in water with different temperature in the range of $25-80^{\circ} \mathrm{C}$. Water uptake was calculated from

$$
\text { water uptake }=\frac{G_{w}-G_{d}}{G_{d}} \times 100 \%
$$
of two new absorption peaks at $1026 \mathrm{~cm}^{-1}$ and
$1083 \mathrm{~cm}^{-1}$, representing the aromatic $\mathrm{SO}_{3} \mathrm{H}$ symmetric and asymmetric stretching vibrations, respectively. This was in close agreement with

Table 1 Overall membrane performance of SPEEK and Nafion membranes

\begin{tabular}{lcccccc}
\hline Membrane & $\begin{array}{c}\mathbf{0} \\
\mathbf{S O}_{3} \mathbf{H}\end{array}$ & $\begin{array}{c}\mathbf{T g} \\
\left({ }^{\circ} \mathbf{C}\right)\end{array}$ & $\begin{array}{c}\text { Water } \\
\text { uptake } \\
(\mathbf{w t .} \%)\end{array}$ & $\begin{array}{c}\text { Proton } \\
\text { conductivity, } \boldsymbol{\sigma} \\
(\mathbf{S} / \mathbf{c m})\left(\times \mathbf{1 0}^{-2}\right)\end{array}$ & $\begin{array}{c}\text { Methanol } \\
\text { permeability, } \mathbf{P} \\
(\mathbf{c m} / \mathbf{s})\left(\times \mathbf{1 0}^{-7}\right)\end{array}$ & $\begin{array}{c}\text { Overall membrane } \\
\text { performance, } \\
(\mathbf{\Phi}=\sigma / \mathbf{P})\left(\times \mathbf{1 0}^{\mathbf{3}}\right)\end{array}$ \\
\hline SPEEK37 & 37 & 155 & 25 & 0.597 & 3.45 & 17.304 \\
SPEEK52 & 52 & 175 & 51 & 1.07 & 5.14 & 20.817 \\
SPEEK60 & 60 & 180 & 82 & 2.71 & 7.59 & 35.704 \\
SPEEK80 & 80 & 200 & 108 & 3.69 & 27.3 & 13.516 \\
Nafion & - & - & 18 & 1.35 & 63.0 & 2.143 \\
\hline
\end{tabular}




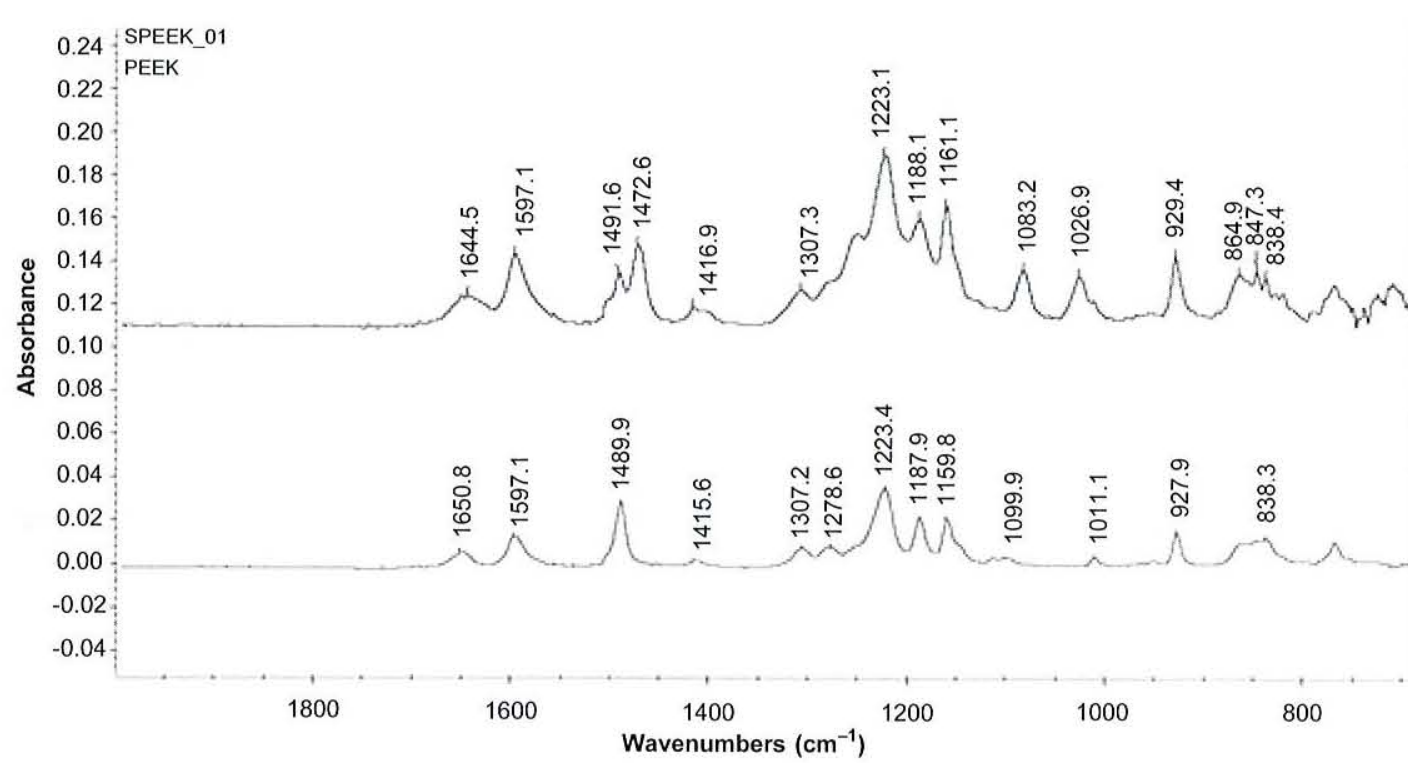

Figure 1 FTIR spectra of PEEK and SPEEK with $60 \%$ degree of sulfonation

$1020 \mathrm{~cm}^{-1}$ and $1080 \mathrm{~cm}^{-1}$ as reported by Gao branes. There are several PEM properties that are et al. [11]. This broadband confirms the presence closely related to the hydrophilicity of the memof sulfonic acid group in the parent PEEK. The branes includes proton conductivity, mechanical peak identified at $1490 \mathrm{~cm}^{-1}$ proved the presence stability and methanol permeability. The loss of

of $\mathrm{C}-\mathrm{C}$ aromatic ring in the PEEK, which referred water corresponds to a drop of proton conducto the $1,2,4-s$ bstulion was similar to the peak reported by Xing et al. [15]. This peak was found to split into two new absorption bands for SPEEK60 at $1472 \mathrm{~cm}^{-1}$ and $1491 \mathrm{~cm}^{-1}$ that presented the aromatic ring between the ether linkages. The significant shifting feature from peak $1490 \mathrm{~cm}^{-1}$ to these two new peaks implied that the sulfonic acid group only attached to the 1,2,4-substitution aromatic ring between the ether linkages ring, which meant only first substitution involved in the reaction. This result was also consistent with the explanation provided by Drioli et al. [16] and Wang et al. [17] The peak observed in PEEK and sulfonated PEEK was at $1223 \mathrm{~cm}^{-1}$ which referred to the aromatic C-O-C absorption [11].

\subsection{Swelling Behavior of SPEEK}

Swelling behavior is a property that is important to determine the capability of membranes to absorb water to facilitate penetrates such as ions and methanol to migrate pass through the memtivity value for almost all PEM. Therefore, high water uptake or high hydrophilic domain in membrane microstructure is crucial in order to produce high proton conductivity. However, excess water uptake can lead to the low dimensional and mechanical property deterioration of membrane due to the soluble nature of membrane in water: Therefore, the water and methano For further understanding of temperature effects on water uptake and swelling ratios of SPEEK membranes, the water uptake and swelling ratios of SPEEK membranes were evaluated as a function of temperature.

The relation between the temperature and water uptake and swelling ratio is illustrates in Figure 2. The result shows that the water uptake raise sharply from room temperature up to $40^{\circ} \mathrm{C}$ and then increase gradually just after that temperature until $80^{\circ} \mathrm{C}$. The changes were due to the increment of intermolecular interaction between the polar groups such as the hydrogc and the sulfonic acid groups via the ionomer effect

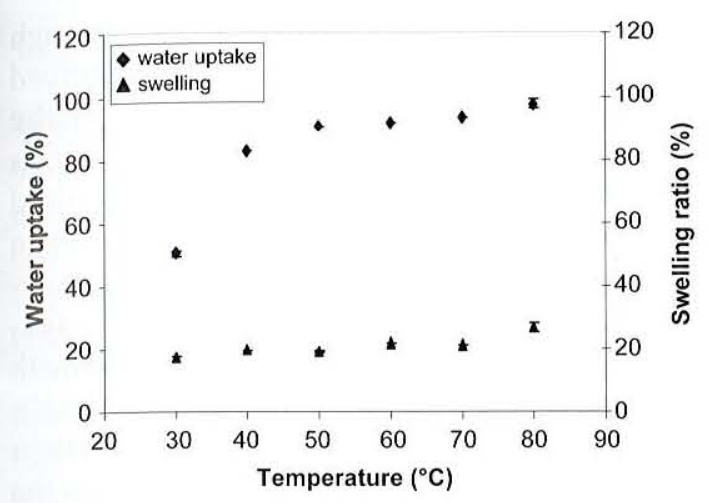

Figure 2 Water uptakes and swelling ratios of SPEEK as a function of temperature

and simultaneously, increase the free volume of water absorption [9]. However, after $80^{\circ} \mathrm{C}$ the membranes tend to dissolve in water. This phenomenon was due to the phase changes from solid in solid backbone tend to stretch the polymer bonds and backbone tend to stretch the polymer bonds and
finally fractured. A comparable finding was finally fractured. A compar.
reported by Cai et al. [18].

The amount of water uptake is also associated with swelling ratio. The swelling effect is one of the important methods to determine the the import mechanical stability of SPEEK membranes. Figure 2 also shows the result of the effects of
temperature on swelling ratio. The result shows temperature on swelling ratio. The result shows room temperature until $80^{\circ} \mathrm{C}$. Similar phenomenon occurred when SPEEK membrane tend to swell just after $80^{\circ} \mathrm{C}$ [18]. The result also clearly shows that there was a significant difference on water uptake as a function of temperature. On contrary, the SPEEK swelling ratio did not give a significant influence throughout the experiment. It was 70\% difference between water uptake value and swelling ratio value when temperature reached $80^{\circ} \mathrm{C}$. This phenomenon showed that although the SPEEK membrane absorbed water as much as $100 \%$ water uptake at the highest temperature but at the same time it still maintain the shape. This behavior exhibited that the ability of SPEEK membrane to absorb water is superior while maintaining its mechanical stability.

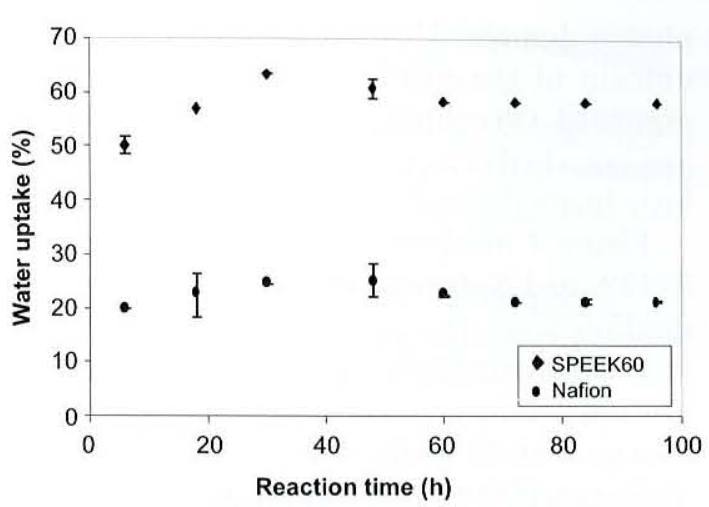

Figure 3 Water uptakes for SPEEK membrane with $60 \%$ DS and Nafion membrane as a function of reaction time

Figure 3 shows the water uptake of SPEEK and Nafion membranes as a function of reaction time. It was observed that both of SPEEK and Nafion membranes had similar trend of curve. Both membranes showed a sharp increment after soaked in water between 6 hours and 30 hours and then decreased gradually and finally remained constant started from 60 hours to 96 hours. This behavior showed that the water uptake increase with increasing reaction time. It was suggested that as the time increased, more water swollen ionic domains produced in the membranes and simultaneously more interconnected to form a network structure developed. The constant water uptake observed for membranes at higher reaction time was due to the diffusion limitation caused by segregation in the ionic domains that showed that the membranes were saturated with water [19].

Figure 3 also shows that the water uptake of SPEEK membranes was outstanding to that of Nafion membrane. The water uptake of SPEEK membranes at constant region showed approximately $65 \%$ higher than Nafion membrane. This was due to the microstructure of the polyme which distributed to two domains; hydrophobic domain represented by the polymer backbone and hydrophilic domain represented by the functional group attached to the polymer ring [20]. From the SPEEK membranes point of view, the presence of aromatic group in the SPEEK polymer backbone presented less pronounce of the hydro- 
phobic domain. Hence, hydrated hydrophilic domain of the SPEEK membranes could be expanded. On contrary to the Nafion membrane, less branched of its perfluorinated polymer backbone limits the hydrophilic domain hydration.

Figure 4 illustrates the methanol uptake of SPEEK and Nafion membranes as a function of reaction time. The methanol uptake of Nafion increased dramatically until it reached the highest value at about $40 \%$ after soaking in water for 30 hours. After 30 hours, the methanol uptake of Nafion membranes started to decrease constantly until 96 hours. On contrary, the methanol uptake of SPEEK membranes went up slowly and then leveled off at $11 \%$ from 72 hours to 96 hours. A significant result was observed that the methanol uptake of Nafion was higher than that of sulfonated PEEK membranes. This was due to the difference in microstructure between Nafion and SPEEK membrane. It was found true by Chang et al. [21] and Kreuer [22] as they reported that the Nafion membrane has high hydrophobicity of the perfluorinated backbone and also high hydrophilicity of the sulfonic acid groups. In the presence of water, this character was more pronounced and consequently increased the hydrophobic/hydrophilic domains of Nafion membrane. The hydrophilic domains in the Nafion membrane which were formed by the presence of sulfonic acid group allowed not only proton and water, but also a smaller polar

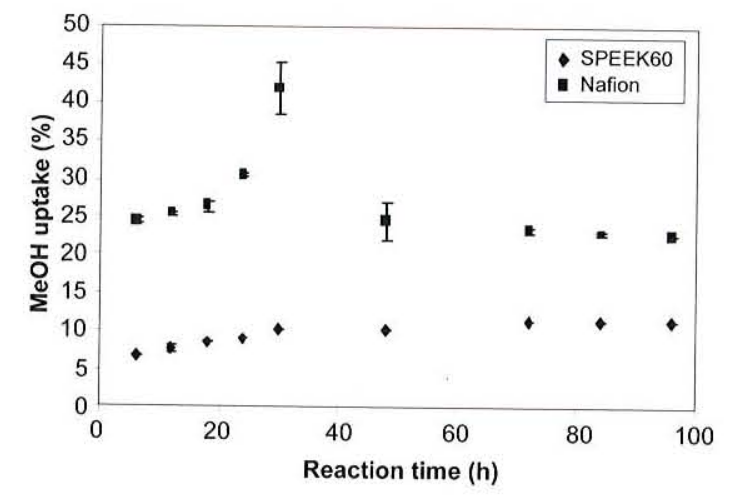

Figure 4 Methanol uptakes for SPEEK with 60\% DS and Nafion membrane as a function of reaction time molecule such as methanol to migrate through his domain. However, the less pronounced hydrophilic-hydrophobic separation of the SPEEK membranes produced narrow channels and a highly branched structure hence minimized the amount of methanol permeated through them [22].

The percentage of the solvent uptake (i.e. water and methanol) of SPEEK membranes with reaction time is plotted in Figure 5. Interestingly, it was observed that the methanol uptake values or the SPEEK membranes were lower than the water uptake values as much as $80 \%$. This was due to the degree of polymeric membrane in solvent that was proportional to the hydrogen bonding capability of the solvent. The hydrogen bonding in methanol is not as strong as it is in water. This can be understood based on the fact that the $\mathrm{O}$ atom does not have as much partial negative charge in methanol as it does in water because the $\mathrm{C}$ atom draws away some of the negative charge. Therefore, the hydrogen atom in methanol does not have as much positive charge as in water. Hence, it may be concluded that the existent of extensive swelling in water is caused by high formation of hydrogen bonding ormed which enhanced the facilitation of the water absorption into the menbras $\mathrm{A}$ simila behavior was observed by Ismail et al. [23] on the sulfonated polystyrene pore-filled electrolyte membranes by electrons induced grafting.

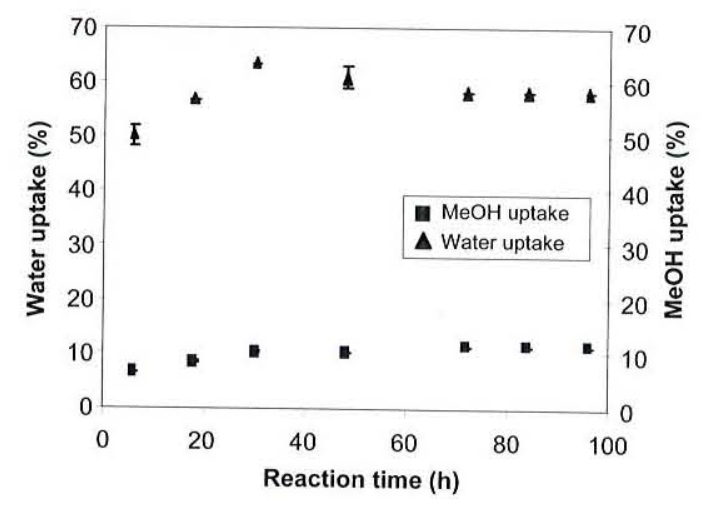

Figure 5 Variation of water uptake and methanol uptake as a function of reaction time for SPEEK membrane with $60 \%$ DS

\subsection{CONCLUSION}

SPEEK membranes with $60 \%$ of SO3H content ing methanol barrier were successfully preping The water uptake as a function prepared. The water uptake as a function of reaction time of SPEEK membranes was highe than that of Nafion membrane. Result showed that SPEEK membranes exhibited lower methanol uptake as much as $75 \%$ as compared to Nafion membrane at the same conditions. Interestingly, the result also showed that SPEEK Intem compared to water uptake SPEEK menbrans with $60 \%$ of DS have performed a high methanol barrier proton exchange membrane for direc methanol fuel cell applications.

\section{ACKNOWLEDGEMENT}

The authors are thankful to Universiti Teknolog Malaysia for granting fellowship for this research work. One of the authors, J. Jaafar is thankful to Ministry of Science, Technology and Innovation, Malaysia for providing financial support through National Science Fellowship scholarship for conducting this research project.

\section{REFERENCES}

[1] Thomassin, J.M., C. Pagnoulle, G. Caldarella A. Germain, and R. Jerome 2006. ConA. Geeso Properties of a Model Proton Exchange Properties of a Model Proton Exchange
Membrane for Fuel Cell Application. J. Membr. Sci. 270: 50-56.

[2] Choi, W.C., J.D. Kim, and S.I. Woo. 2001 Modification of Proton Conducting Membrane for Reducing Methanol Crossover in Direct Methanol Fuel Cell. I. Power Sources. 96: 411-414.

[3] Kopitzke, R. 1999. Investigation o Sulfonated High Temperature Polymers a Proton Exchange Membane Electrolytes. $\mathrm{Ph} . \mathrm{D}$. Dissertation. Florida Institute of Technology.

[4] McPeak, J L 1999 Solvent-Induced Crystallization of Poly(ether ether ketone).
Ph.D. Dissertation. Virginia Polytechnic Institute and State University

[5] Li, L., J. Zhang, and Y. Wang. 2003. Sulfonated Poly (ether ether ketone) Membranes for Direct Methanol Fuel Cell. J. Membr. Sci. 226: 159-167

[6] Huang, R.Y.M., P. Shao, X. Feng, and C.M. Burns. 2001. Pervaporation Separation of Water/Isopropanol Mixture Using Sulfonated Poly(ether ether ketone) [SPEEK] Membranes: Transport Mechanism And Separation Performance. $J$ Membr. Sci. 192: 115-127.

[7] Kobayashi, T., M. Rikukawa, K. Sanui, and N. Ogata. 1998. Proton-Conducting Polymers Derived from Poly(ether ether ketone) and Poly(4-Phenoxybenzoyl-1,4Phenylene). Solid State Ionics. 106: 219225.

[8] Shao, P. 2003: Pervaporation Dehydration Membranes based on Chemically Modified Poly(ether ether ketone). Ph.D. Thesis University of Waterloo.

[9] Zaidi, S.M.J., S.D. Mikhailenko, G.P Robertson, M.D. Guiver, and S. Kaliaguine 2000. Proton Conducting Composite Membranes from Poly(ether ether ketoc) and e) and Heteropolyacids for Fuel Cell Applications J. Membr. Sci. 173: 17-34.

10] Bailly, C., D.J. William, F.E. Karasz, and W.J. McKnight. 1987. The Sodium Salts of Sulfonated PEEK: Preparation and Characterization. Polymer. 28: 1009-16.

[11] Gao, Y, G.P. Robertson, M.D. Guiver, X Jian, S.D. Mikhailenko, K. Wang et al. 2003. Sulfonation of Poly (Phthalazinones) With Fuming Sulfuric Acid Mixtures for Proton Exchange Membrane Materials. J. Membr Sci. 227: 39-50.

12] Gil, M., X. Ji, X. Li, H. Na, J.E. Hampsey, and Y. Lu. 2004. Direct Synthesis of Sulfonated Aromatic Poly(ether ether ketone) Proton Exchange Membranes for Fuel Ce Applications. J. Membr. Sci. 234: 75-81.

13] Dai, Y., X. Jian, S. Zhang, and M.D. Guiver 2001. Thermostable Ultrafiltration and Nanofiltration Membranes from Sulfonated Poly(Phthalazinones Ether Sulfone Ketone). J. Membr. Sci. 188: 195-203. 
[14] Jaafar, J., A.F. Ismail, and A. Mustafa. 2006. Physicochemical Study of Poly(ether ether ketone) Electrolyte Membranes Sulfonated with Mixtures of Fuming Sulfuric Acid and Sulfuric Acid for Direct Methanol Fuel Cell Application. Mater. Sci. Eng., A. 460-461: 475-484.

[15] Xing, P., G.P. Robertson, M.D. Guiver, S.D. Mikhailenko, K. Wang, and S. Kaliaguine. 2004. Synthesis and Characterization of Sulfonated Poly(ether ether ketone) for Proton Exchange Membranes. J. Membr. Sci. 229: 95-106.

[16] Drioli, E., A. Regina, M. Casciola, A. Oliveti, F. Trotta, and T. Massari. 2004. Sulfonated PEEK-WC Membranes for Possible Fuel Cell Applications. J. Membr. Sci. 228: 139-148.

[17] Wang, F., M. Hickner, Y.S. Kim, T.A. Zawodzinski, and J.E. McGrath. 2002. Direct Polymerization of Sulfonated Poly (Arylene Ether Sulfone) Random (Statistical) Copolymers: Candidates for Proton Exchange Membranes. J. Membr. Sci. 197: 231-242.

[18] Cai, H., S. Zhong, C. Zhao, G. Zhang, X. $\mathrm{Li}$, and H. Na. 2007. Properties of Composite Membranes Based on Sulfonated Poly(ether ether ketone)s (SPEEK)/ Phenoxy Resin (PHR) for Direct Methanol
Fuel Cells Usages. J. Membr. Sci. 297: 162173.

[19] Nasef, M.M, N.A. Zubir, A.F. Ismail, K.Z.M. Dahlan, H. Saidi, and M. Khayet. 2005. Preparation of Radiochemically PoreFilled Polymer Electrolyte Membranes for Direct Methanol Fuel Cell. J. Power Sources. 156: 200-210.

[20] Lee, H.C., H.S. Hong, Y.M. Kim, S.H. Choi, M.Z. Hong, H.S. Lee et al. 2004. Preparation and Evaluation of SulfonatedFluorinated Poly(Arylene Ether)s Membranes for Proton Exchange Membrane Fuel Cell (PEMFC). Electrochim. Acta. 49: 2315-2323.

[21] Chang, J.H., J.H. Park, C.S. Kim, and O.O. Park. 2003. Proton-Conducting Composite Membranes Derived from Sulfonated Hydrocarbon and Inorganic Materials. $J$. Power Sources. 124: 18-25.

[22] Kreuer, K.D. (2001). On the Development of Proton Conducting Polymer Membranes for Hydrogen and Methanol Fuel Cells. J. Membr. Sci. 185: 29-39.

[23] Ismail, A.F., N. Zubir, M. M. Nasef, K.M. Dahlan, and A. R. Hassan. 2005. PhysicoChemical Study of Sulfonated Polystyrene Pore-Filled Electrolyte Membranes by Electrons Induced Grafting. J. Membr. Sci. 254: 189-196. 